\title{
POTENSI EKOWISATA PESISIR BERBASIS KEARIFAN LOKAL
}

\author{
Syahlan Mattiro' ${ }^{1}$, Nasrullah ${ }^{2}$, Reski $\mathbf{P}^{3}$ \\ Program Studi Pendidikan Sosiologi, FKIP, Universitas Lambung Mangkurat, Indonesia ${ }^{1,2,3}$ \\ ${ }^{1}$ lintangmattiro@ulm.ac.id, ${ }^{2}$ eje_jela@yahoo.com, ${ }^{3}$ reski@ulm.ac.id
}

\begin{abstract}
The purpose of this research is to take pictures in the form of mapping the potential of coastal ecotourism based on the local wisdom of the Mandar tribe on the island of Kerayaan. This research was conducted using qualitative research methods using ethnographic approaches. By using qualitative research methods, it can be seen the meaning behind the data obtained in the field, and it can be analyzed which the results of this research can be used as an alternative option in problem solving. The results of this study succeeded in capturing some of the cultural potentials of the Mandar tribe that could support the development of coastal ecotourism based on local wisdom on Kerayaan Island, namely the Katir Boat as the identity of Mandar Fishermen, Pamacca as a portrait of Mandar martial arts. The development of coastal tourism and the culture of the mandar tribe on Kerayaan Island, needs careful planning by taking into account existing environmental conditions and can affect coastal tourism activities. Identification of current environmental conditions is important as a basis for taking steps to develop coastal tourism in the future. The environmental conditions that will be referred to consist of two components, namely internal environmental conditions and external environmental conditions. The internal environment concerns the condition / description of the resources in the planned area, while the external environment concerns the external conditions that can enter / touch and is expected to have a strong influence on the development of the planned area for coastal and cultural tourism purposes, such as social, political, economic and technological conditions. , energy and natural resource conservation.
\end{abstract}

\section{Keywords: Ecotourism, Coastal, Local Wisdom}

\begin{abstract}
Abstrak. Tujuan dari penelitian ini adalah untuk memotret dalam bentuk pemetaan potensi ekowisata pesisir berbasis kearifan lokal suku Mandar yang terdapat di pulau Kerayaan. Penelitian ini dilakukan dengan menggunakan metode penelitian kualitatif dengan menggunakan pendekatan-pendekatan Etnografi. Dengan menggunakan metode penelitian kualitatif dapat diketahui makna yang ada di balik data-data yang diperoleh di lapangan, dan dapat dianalisis yang mana hasil dari penelitian ini dapat dijadikan salah satu pilihan alternatif dalam pemecahan masalah. Hasil penelitian ini berhasil memotret beberapa potensi budaya suku Mandar yang dapat mendukung pengembangan ekowisata pesisir berbasis kearifan lokal di Pulau Kerayaan yaitu Perahu Katir sebagai identitas Nelayan Mandar, Pamacca sebagai potret beladiri Mandar. Pengembangan wisata pesisir dan budaya suku mandar di Pulau Kerayaan, perlu perencanaan secara matang dengan memperhatikan kondisi lingkungan yang ada dan dapat mempengaruhi kegiatan wisata pesisir. Identifikasi terhadap kondisi lingkungan saat ini penting dilakukan sebagai dasar dalam pengambilan langkah untuk pengembangan wisata pesisir ke depan. Adapun kondisi lingkungan yang akan dimaksud terdiri atas dua komponen yakni kondisi lingkungan internal dan kondisi lingkungan eksternal. Lingkungan internal menyangkut kondisi/gambaran sumberdaya di daerah yang direncanakan, sedangkan lingkungan eksternal mengenai keadaan di luar yang dapat memasuki/menyentuh dan diperkirakan dapat berpengaruh kuat terhadap pengembangan daerah yang direncanakan untuk keperluan wisata pesisir dan budaya seperti kondisi sosial, politik, ekonomi, dan teknologi, energi dan konservasi sumberdaya alam.
\end{abstract}

Kata Kunci: Ekowisata, Pesisir, Kearifan lokal

\section{PENDAHULUAN}

Pembangunan di kawasan pesisir dan pulau-pulau kecil mempunyai peranan penting dan strategis dalam pembangunan nasional, utamanya sebagai penghasil devisa, meningkatkan kesempatan kerja, meningkatkan penghasilan dan taraf hidup, serta menstimulasi sektor-sektor yang memanfaatkan kawasan pesisir. Secara umum pihak yang berkepentingan di kawasan pesisir dan pulau-pulau kecil dikategorikan dalam sektor pertanian/perikanan, pariwisata, pertambangan, perhubungan laut, industri maritim dan konservasi. Sebagai negara maritim dan kepulauan terbesar di dunia, Indonesia memiliki potensi sumber daya kelautan yang sangat besar dan beragam. Indonesia merupakan pusat keanekaragaman hayati laut tertinggi di dunia dengan lebih dari 4500 spesies ikan, lebih dari 70 genus hewan karang, $18 \%$ terumbu karang dunia, 30\% hutan bakau dunia, 13 spesies lamun dari 16 spesies di dunia, dan spesies rumput laut terbanyak di dunia. Indonesia memiliki 17.508 pulau dengan panjang garis pantai $81.000 \mathrm{~km}$ (Bengen, 2001). 
Luas wilayah perairan Indonesia sebesar 5,8 juta $\mathrm{km}^{2}$ yang terdiri dari 3,1 juta $\mathrm{km}^{2}$ Perairan Nusantara dan $2,7 \mathrm{~km}^{2}$ Perairan Zona Ekonomi Eksklusif Indonesia (ZEEI) atau 70 persen dari luas total Indonesia (S., 2001)

Pariwisata adalah salah satu potensi yang kini banyak digali dan dikembangkan di banyak negara. Ada peningkatan kecenderungan pasar pariwisata internasional untuk berwisata di kawasan yang masih alami. Kecenderungan ini memberi peluang bagi pengembangan pariwisata Indonesia karena Indonesia merupakan negara kepulauan terbesar di dunia yang kaya akan keanekaragaman hayati, memiliki panjang garis pantai lebih dari $81.000 \mathrm{~km}$ dan 17.504 pulau, di mana 10.000 pulau diantaranya merupakan pulau-pulau kecil, bahkan sangat kecil, belum bernama dan tidak berpenghuni. Pulau-pulau kecil memiliki potensi dimanfaatkan untuk kegiatan pariwisata dalam bentuk wisata bahari (marine tourism) ataupun ekowisata (Nurhayati, 2018)

Indonesia juga memiliki seni budaya yang beraneka ragam dengan suku bangsa yang beragam. Kondisi iklim di Indonesia juga cukup mendukung untuk kegiatan wisata. Dengan potensi tersebut, maka Indonesia memiliki peluang yang besar untuk mengembangkan sektor pariwisata khususnya bidang ekowisata bahari dan budaya.

Upaya pemerintah daerah dan provinsi Kalimantan Selatan dalam menata ruang yang tertuang dalam dokumen Rencana Zonasi membawa dampak yang positif dalam pengembangan ruang (wilayah) khususnya zona wisata di pulau- pulau kecil Kabupaten Kotabaru. Meski demikian, potensi wisata pesisir dan objek wisata lainnya yang ada di pulau-pulau kecil seperti di Pulau Kerayaan dan pulau- pulau lainnya belum dimanfaatkan sebagai zona wisata seperti yang diamanatkan dalam dokumen ini, malahan potensi terumbu karang sebagai objek wisata ditambang sebagai bahan bangunan.

Kegiatan wisata yang akan dikembangkan akan berhadapan dengan berbagai kegiatan perekonomian lainnya seperti bidang pertanian, pemukiman, perikanan dan industri yang berpotensi meningkatkan tekanan terhadap ekologi(C., 2002). Potensi yang ada seharusnya memberi dampak ekonomi bagi masyarakat setempat dan menambah pendapatan daerah bagi pemerintah Kabupaten Kotabaru.

Permasalahan utama yang ada pulaupulau ini adalah belum teridentifikasinya potensi-potensi wisata dan belum ditemukan Model yang tepat khususnya wisata pesisir yang unik dan menarik. Permasalahan lainnya antara lain kurangnya sarana dan prasarana yang layak guna mendukung kegiatan ekowisata, kurang kreatifnya pengembangan atraksi budaya, kurangnya promosi dan pemasaran wisata dari pemerintah setempat yang dikarenakan belum adanya sumber dana untuk membiayai pengembangan wisata tersebut. Dari berbagai permasalahan ini, tentunya pengembangan ekowisata pulau-pulau ini memiliki hambatan namun dengan adanya penelitian ini diharapkan dapat menjadi masukan untuk menyelesaikan berbagai permasalahan tersebut.

Selain potensi terumbu karang dan pantai, potensi lain yang dimiliki pulau-pulau ini adalah wisata budaya pesisir antara lain terdapat di Pulau Kerayaan berupa budaya upacara adat yang merepresentasikan laut yang merupakan salah satu acara adat sebagai tanda syukur atas melimpahnya hasil laut di Kecamatan Pulau Laut Kepulauan (ibukota kecamatan Pulau Kerayaan).

Ditinjau dari kesukuan ternyata penduduk di pulau ini mayoritas Suku Mandar, yang tidak lain dulunya merupakan pendatang dari daratan Sulawesi dan menetap tinggal di pulau-pulau yang ada di Kabupaten Kotabaru dimana budayanya sangat berorientasi pada laut. Di kawasan timur Indonesia, Mandar tidak berbeda dengan suku lain yang yang juga memiliki budaya yang berorientasi ke laut, misalnya suku Bugis, Makassar dan Buton yang ketiganya dikenal sebagai masyarakat maritim (Anwar., 1998), disamping itu kemiripankemiripan suku Mandar dengan ketiga suku diatas, ini dapat kita temukan dengan melihat sistem budaya dengan cara pembuatan perahu, pantangan-pantangan yang tidak boleh dilanggar oleh nelayan dan ritual peresmian perahu baru yang akan diturunkan melaut.

Dalam buku The Bugis, yang ditulis oleh Christian Pelras(Pelras, 2006), Ia mengatakan bahwa orang Bugis bukanlah pelaut ulung, "orang Bugis sebenarnya adalah pedagang. Laut 
dan kapal hanyalah media atau sarana yang digunakan untuk memperlancar aktivitas perdagangan mereka. Kalau mau menyebut pelaut ulung, maka yang paling tepat adalah orang Mandar".Masyarakat Mandar adalah masyarakat pelaut. Berlayar bagi mereka erat kaitannya dengan mata pencaharian utama. Mata pencaharian ini mungkin ada hubungannya dengan posisi geografis masyarakat ini dikelilingi laut dan kondisi alam yang kurang subur untuk pertanian. Oleh karena itu, kegiatan dan orientasi hidup mereka banyak terfokus ke laut. Mereka mengembangkan sistem sosial budaya yang berbasis kelautan.

Bagi wisatawan selain wisata pesisir yang ditawarkan tentunya juga ingin mendapatkan atraksi-atraksi lainnya yang ada di wilayah tersebut. Oleh karena itu perpaduan wisata yang dikelola dengan baik dapat menjadikan pulau ini menjadi primadona sebagai tujuan wisata bagi wisatawan, baik lokal maupun internasional. Hashimoto (Hashimoto, 1999) yang menyebutkan bahwa aset sumber daya alam dan budaya merupakan daya tarik wisata dan mempunyai konsekuensi keberlanjutan daerah tujuan, dengan kata lain kelangsungan kegiatan ekowisata sangat tergantung pada kualitas sumber daya alam dan lingkungan fisik.

\section{METODE}

Penelitian ini dilakukan dengan menggunakan metode penelitian kualitatif dengan menggunakan pendekatan-pendekatan Etnografi. Etnografi adalah merupakan pekerjaan untuk mendeskripsikan suatu kebudayaan (Spradley, 1997). Selain itu, alasan metode penelitian kualitatif digunakan untuk mendapatkan data yang mendalam, lebih lengkap, kredibel, dan bermakna sehingga tujuan penelitian untuk memperoleh gambaran penelitian secara luas, menyeluruh, holistik (utuh) dan mendalam dapat tercapai. Dengan menggunakan metode penelitian kualitatif dapat diketahui makna yang ada di balik data-data yang diperoleh di lapangan, dan dapat dianalisis yang mana hasil dari penelitian ini dapat dijadikan salah satu pilihan alternatif dalam pemecahan masalah.

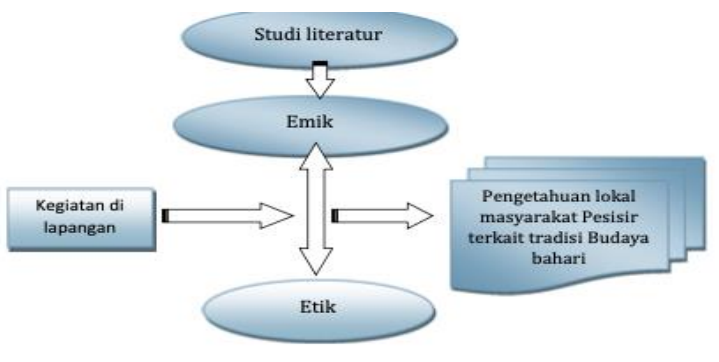

Skema Penelitian

Langkah-langkah Penjaringan data: Pertama: Tim peneliti turun ke lapangan mendatangi lokasi penelitian selanjutnya menemui Informan yang sudah dipilih secara purposive dengan tujuan untuk mendapatkan informasi baik secara emik ataupun etik. Dari pandangan etik dan emik penelitian ini akan mendapatkan Pengetahuan kearifan lokal warga mengenai perilaku budaya dalam kegiatan berbentuk ritual kebaharian. Adapun proses pengumpulan data dengan melakukan teknik pengumpulan data dilakukan dengan cara Observasi, Wawancara, Dokumentasi foto, dan Data literatur.

Kedua: Observasi digunakan untuk menggali data tentang gambaran fisik lokasi Pulau Kerayaan dan segala aktivitas masyarakat terkait dengan perilaku budaya dalam kegiatan berbentuk ritual kebaharian mereka. Percakapan atau komunikasi masyarakat dalam bahasa lokal yang didengar kapan saja, di mana saja, dan dari siapa saja, karena percakapan inilah menyimpan informasi berupa istilah-istilah lokal yang mengandung makna kearifan lokal (Ahimsa Putra HS., 2008). Ketiga: Melakukan dokumentasi visual berupa foto untuk menggali data tentang aktivitas masyarakat terkait pelaksanaan ritual budaya pesisir.

Analisis data ialah proses menyusun data agar dapat ditafsirkan. Menyusun data berarti menggolongkannya (mengkategorikannya) dalam pola atau tema. Tafsiran atau interpretasi artinya memberikan makna terhadap analisis, menjelaskan pola atau kategori, serta mencari hubungan antara berbagai konsep. Dari berbagai definisi tersebut dapat disimpulkan bahwa analisis data adalah kegiatan analisis mengkategorikan data untuk mendapatkan pola hubungan, tema, menafsirkan apa yang bermakna, serta menyampaikan atau 
melaporkannya kepada orang lain yang berminat.

Pada prinsipnya analisis data kualitatif dapat dilakukan bersamaan dengan proses pengumpulan data. Teknik analisis yang dilakukan dengan menggunakan teknik analisis data berupa Reduksi data, Display data dan Verifikasi data. Untuk mengetahui kondisi sosial-budaya dan ekonomi pada lokasi penelitian dilakukan pengambilan data primer melalui pengamatan langsung dan wawancara, sedangkan data sekunder melalui berbagai sumber yaitu lembaga-lembaga instansi terkait.

\section{HASIL DAN PEMBAHASAN}

Dalam konteks pembangunan nasional di era sekarang ini, kawasan pesisir dan pulau-pulau kecil mempunyai peranan penting dan strategis, terutama sebagai penghasil devisa, meningkatkan kesempatan kerja, meningkatkan penghasilan dan taraf hidup, serta menstimulasi sektor-sektor yang memanfaatkan kawasan pesisir. Secara umum pihak yang berkepentingan di kawasan pesisir dan pulau-pulau kecil dikategorikan dalam sektor pertanian/perikanan, pariwisata, pertambangan, perhubungan laut, industri maritim dan konservasi. Sektor pariwisata merupakan kegiatan yang berkembang cepat di wilayah pesisir dan pulaupulau kecil, sehingga dapat meningkatkan pendapatan daerah. Hal ini dikarenakan kawasan wisata memiliki kekayaan dan keragaman yang tinggi dalam berbagai bentuk sumber daya alam, sejarah, adat, budaya dan berbagai sumberdaya dengan keterkaitan ekologisnya (E., 2002).

Saat ini banyak nilai budaya yang semakin dilupakan dan berkurang pelestariannya. Padahal kebudayaan dapat juga menghasilkan pemasukan bagi pemerintah daerah setempat khususnya pada sektor pariwisata. Wisata budaya perlu dikembangkan dengan tujuan untuk melestarikan unsur budaya yang ada di suatu wilayah. Perkembangan pariwisata tidak hanya berpengaruh terhadap sosial budaya masyarakatnya saja tetapi juga terhadap kehidupan ekonomi, religi, atau pengetahuan masyarakat mengenai sesuatu yang unik dalam suatu wilayah.

Berdasarkan hasil pengamatan dan wawancara dapat diketahui bahwa terdapat beberapa potensi budaya berbasis kearifan lokal warga masyarakat Pulau kerayaan yang mayoritas adalah suku Mandar yang dapat mendukung pengembangan ekowisata pesisir dan budaya di Pulau Kerayaan, meski demikian potensi ini juga diikuti dengan tantangan dalam pengembangannya.

\section{Perahu Katir dan Identitas Nelayan Mandar}

Katir sendiri dalam Bahasa Mandar penyebutan dalam konteks perlombaan, perlombaan yang dimaksud adalah perlombaan ketangkasan dalam mengemudikan atau melayarkan perahu nelayan tradisional Mandar dalam kegiatan festival "Katir Race" yang diadakan setiap tahun bahkan bisa diadakan beberapa kali dalam satu tahun di Pulau Kerayaan Lepa-lepa atau perahu tradisional nelayan Mandar ini merupakan perahu tradisional yang memiliki ciri spesifik dalam artian memiliki perbedaan dengan perahu tradisional Mandar "Sandeq" yang ada di Provinsi Sulawesi Barat. Perbedaan yang paling mencolok bisa terlihat dari ukuran/besarnya perahu, bentuk perahu, cadik yang ada pada perahu dan pelampung yang dipasang di kanankiri perahu sebagai penyeimbang. Akan tetapi hasil penelitian ini hanya membatasi pada perahu tradisional Mandar dan tidak sama sekali akan memberi penjelasan pada perbedaan masingmasing dari dua jenis perahu nelayan walaupun sama-sama perahu Orang Mandar itu sendiri.

Penyebutan "Katir" pada perahu lepalepa oleh Orang Mandar di Pulau Kerayaan adalah untuk membedakan penyebutan yang sama terhadap perahu nelayan lainnya. Untuk penyebutan "lepa-lepa niwoseang" diperuntukan pada perahu sampan yang digerakan oleh tenaga manusia dengan menggunakan dayung, ada juga penyebutan "lepa-lepa Powau" untuk perahu nelayan yang digerakan oleh tenaga angin melalui penggunaan layar, dari jenis perahu ini lah merupakan cikal bakal dari perahu "Katir" dikarenakan "lepa-lepa Powau" itu sendiri berubah penyebutan ketika sudah didaftarkan untuk mengikuti ajang perlombaan "Katir Race". Pada momentum seperti inilah "lepa-lepa Powau" naik kelas menjadi perahu tradisional bergengsi apa lagi mendapatkan juara dalam mengikuti ajang lomba "Katir Race", dengan 
sendirinya perahu tersebut akan disimpan secara khusus dan akan diturunkan ke laut lagi hanya pada saat ada kegiatan lomba.

Tradisi lomba perahu Katir adalah tradisi balapan atau lomba perahu Katir yang biasa diselenggarakan antara bulan Juli-Agustus setiap tahun di Pulau Kerayaan, dan akan dijadikan wisata pesisir andalan Kabupaten Kotabaru, Provinsi Kalimantan Selatan. Katir Race (lomba perahu Katir) merupakan kegiatan tahunan yang sudah dijadwalkan dalam agenda kegiatan pariwisata Kabupaten Kotabaru.

Kegiatan tersebut merupakan jenis kegiatan pesisir yang menyerupai jenis kegiatan lomba perahu layar. Selain diikuti oleh peserta dari daerah sekitar Kabupaten Kotabaru, kegiatan ini juga diikuti oleh peserta dari luar daerah. Lomba tersebut terbuka untuk umum, tidak hanya terbatas untuk warga sekitar saja. Lomba perahu Katir merupakan satu-satunya yang ada di Kotabaru dan tidak ada satu daerah lainnya di Indonesia yang menggelar event serupa

\section{Pamacca':Potret Seni Bela Diri Mandar.}

Pencak silat atau silat adalah suatu seni beladiri tradisional yang berasal dari Indonesia. Pencak silat sebagai bagian dari kebudayaan Indonesia berkembang sejalan dengan sejarah perkembangan masyarakat Indonesia. Seni beladiri pencak silat secara luas telah dikenal di Indonesia, bahkan mulai berkembang ke negara tetangga seperti Malaysia, Brunei, Singapura, Filipina selatan, dan Thailand selatan, tepatnya di provinsi Pattani, sesuai dengan penyebaran dan perkembangan suku bangsa Melayu Nusantara (Kumaidah, n.d.). Pencak Silat dalam Bahasa lokal Orang Mandar di Pulau Kerayaan menyebutnya "Pamacca". Dalam pelaksanaannya, "Pamacca" ini dipraktekan atau diperagakan memiliki 2 jenis pelaksanaan. Pertama: Pelaksanaan Pamacca untuk umum, biasanya dilaksanakan untuk upacara hajatan/syukuran seseorang, pengantenan ataupun setelah selesai sunatan. Kedua: Pamacca' dilaksanakan karena warisan keturunan dalam 1 lingkup keluarga/Famili yang disebut dalam Bahasa Mandar Pa'bayoang, pada kategori kedua ini, mengandung sarat makna yang prakteknya harus melalui ritual-ritual yang diyakini Orang Mandar. Dari hasil temuan lapangan Penelitian, ternyata praktek Pamacca' pada unsur ritual ini yang menjadi analisis penting bagi tim peneliti dimana didalamnya ditemukan dimensi supranatural yaitu "Pa'bayoang". Pa'bayoang menurut versi mereka adalah keluarga mereka yang memiliki keturunan Suku Bajau atau Bayo.

Langkah-langkah pelaksanaan ritual Pamacca' dikarenakan ada unsur Pa'bayoang dimulai dengan mempersiapkan:

1) Mempersiapkan sesajen berupa 7 (tujuh) rupa/macam kue-kue tradisional Mandar dan yang harus ada: sokkol, salluang kaiyyang, tallo', anjoro mangura, cucur, salluang Nabi.

2) Menyiapkan Kapal/kelotok yang akan digunakan untuk membawa semua bahanbahan makanan tersebut berkeliling di laut. Sebelum semua bahan makanan tersebut dinaikkan ke kapal, maka terlebih dahulu diadakan do'a bersama dirumah yang melaksanakan kegiatan Pamacca'.

3) Saat prosesi ritual di laut dilaksanakan, kapal melakukan putaran sebanyak 7 kali keliling dengan membaca ayat-ayat suci $\mathrm{Al}$ Qur'an. Selama proses Kapal/klotok berkeliling, bunyi-bunyian dari alat-alat Pamacca' berupa gendang dan Gong tidak boleh terputus sampai tibanya kapal kembali ke pantai.

4) Saat Kapal pembawa ritual laut sampai di pinggir pantai, semua bahan-bahan berupa kue-kue harus habis dimakan di pantai, tidak boleh ada yang tersisa dibawa kembali ke rumah yang melaksanakan acara.

5) Tahap terakhir adalah dimulainya peragaan Pamacca' yang biasanya di halaman rumah atau di dalam ruang rumah itu sendiri.

6) Pada saat berlangsung Pamacca', tuan rumah sebagai pelaksana acara menyimburkan Banno' kepada pemain, ini dimaknai sebagai penghormatan kepada para petarung.

7) Pemain Pamacca' wajib menggunakan Kopiah karena menurut versi mereka, peci/songkok menunjukkan identitas manusia Islam.

\section{KESIMPULAN}

Adapun kesimpulan dari hasil penelitian ini adalah bahwa terdapat beberapa potensi 
budaya suku Mandar yang dapat mendukung pengembangan ekowisata pesisir berbasis kearifan lokal di Pulau Kerayaan yaitu Perahu Katir sebagai identitas Nelayan Mandar, yang mana Katir sendiri dalam Bahasa Mandar penyebutan dalam konteks perlombaan, perlombaan yang dimaksud adalah perlombaan ketangkasan dalam mengemudikan atau melayarkan perahu nelayan tradisional Mandar dalam kegiatan festival "Katir Race" yang diadakan setiap tahun bahkan bisa diadakan beberapa kali dalam satu tahun di Pulau Kerayaan dan Pamacca sebagai potret beladiri Mandar, Dalam pelaksanaannya, "Pamacca"” ini dipraktekan atau diperagakan memiliki 2 jenis pelaksanaan. Pertama: Pelaksanaan Pamacca untuk umum, biasanya dilaksanakan untuk upacara hajatan/syukuran seseorang, pengantenan ataupun setelah selesai sunatan. Kedua: Pamacca' dilaksanakan karena warisan keturunan dalam 1 lingkup keluarga/Famili yang disebut dalam Bahasa Mandar Pa'bayoang, pada kategori kedua ini, mengandung sarat makna yang prakteknya harus melalui ritual-ritual yang diyakini Orang Mandar.

\section{SARAN}

Perlunya penelitian lebih lanjut untuk melihat langkah strategis pemerintah daerah dalam mengembangkan ekowisata pesisir berbasis kearifan lokal di Pulau Kerayaan. Hal tersebut dinilai penting untuk mengidentifikasi penyebab sampai hari ini ekowisata yang ada di pulau tersebut belum mampu mengglobal dan dikenal banyak orang padahal pulau tersebut sangat potensial.

\section{UCAPAN TERIMA KASIH}

Peneliti mengucapkan terima kasih kepada Universitas Lambung Mangkurat yang telah mendanai penelitian ini melalui Program Dosen Wajib Meneliti Tahun 2020.

\section{DAFTAR PUSTAKA}

Ahimsa Putra HS. (2008). Ilmuwan Budaya dan Revitalisasi Kearifan Lokal Tantangan Teoritis dan Metodologis. Fakultas Ilmu Budaya.

Anwar. (1998). Pelayaran Niaga Orang Buton Pada Abad XX. Hasil Penelitian yang dibiayai oleh PSI Lemlit Universitas Terbuka.

Bengen, D. G. (2001). Pedoman Teknis Pengenalan dan Pengelolaan Ekosistem Mangrove. Pusat Kajian Sumberdaya Pesisir dan Lautan. Institut Pertanian Bogor. Bogor, Indonesia.

C., R. (2002). Equity, Management, Power Sharing and Sustainability Issues of The New Tourism. Tourism Management, Vol 23: 17.

E., L. N. (2002). Pariwisata Bahari: Pemanfaatan Potensi Wilayah Pesisir dan autan. Makalah.

Fitri Alfia, N. (2019). Hubungan Sosial Nelayan Purse Sein dengan Masyarakat di Desa Pulau Kerayaan Kecamatan Pulau Laut Kepulauan Kabupaten Kotabaru.

Hashimoto, A. (1999). Comparative Evolutionary Trends in Environmental Policy: Reflection on Tourism Development. International Journal of Tourism Research ., Vol 1: 195.

Kumaidah, E. (n.d.). Penguatan Eksistensi Bangsa Melalui Seni Bela Diri Tradisional Pencak Silat. Google Scholar

Nurhayati, S. Q. (2018). Implementasi Kebijakan Pengembangan Pariwisata Berkelanjutan Di Karimunjawa. Jurnal Masalah-Masalah Sosial, Vol 9 No 2.

Pelras, C. (2006). The Bugis. Nalar.

S., B. (2001). Teknik AnalisisPembangunan Wilayah Pesisir dan Lautan. Pradnya Paramita.

Spradley, J. P. (1997). Metode Etnografi. Terjemahan oleh Misbah Yulfa Elisabeth. PT Tiara Wacana Yogya. 